\title{
Influence of extraction method on antioxidant properties of Rheum ribes root extract
}

\author{
Dilek BILGIC ALKAYA*, ${ }^{1}$ Serap AYAZ SEYHAN, ${ }^{1}$ and Busra Nagihan OZTURK ${ }^{2}$ \\ ${ }^{I}$ Marmara University, Faculty of Pharmacy, Department of Analytical Chemistry, Istanbul, Turkey \\ ${ }^{2}$ Marmara University, Institute of Health Sciences, Istanbul, Turkey
}

\begin{abstract}
Rheum species are important medicinal herbs, often used in pharmacological research, due to the presence of anthracene derivatives in the subterranean parts of the plant. In this study, we intended to assess its antioxidant capacity, in correlation with the method of extraction. For this purpose, Rheum ribes extraction was realized with four solvents of different polarities (50\% methanol, $70 \%$ ethanol, $80 \%$ acetonitrile, and petroleum ether). We used different extraction techniques, such as orbital shaker, ultrasonic stirrer, microwave, and Soxhlet extraction, and the total phenolic content of the Rheum ribes extracts was determined by modified Folin-Ciocalteu method. The reducing power and radical scavenging activity of the extracts were also evaluated. The results shown that the antioxidant activity of the extracts depends on the extraction methods especially through the used solvent and decreases in the order: ethanol > methanol > acetonitrile $>$ petroleum ether.
\end{abstract}

Keywords: Rheum ribes; antioxidant activity; Folin-Ciocalteu assay; DPPH; FRAP.

\section{Introduction}

In the developing world, the tendency towards natural antioxidants has increased due to the harmful effects of synthetic antioxidant use on the health. Hence, the researches on the antioxidant components in root, leaf and fruit of plant material are increasing day by day. Rheum ribes L. (Polygonaceae) is eaten as a vegetable, being the only native Rheum species growing in Eastern of Turkey. Its young shoots and roots are widely used in folk medicine due to pharmacological properties, such as promote digestion, improve appetite, treat diarrhea, and as stomachic, antiemetic [1,2]. Rheum ribes enhances the memory in old patients. Extract of root and stem of Rheum ribes has high antioxidant activity. The findings reveal that foods containing antioxidants delay the progress of Alzheimer's disease probably due to prevention or neutralization of detrimental effects of free radicals [3]. There are many assays in vitro used to measure the antioxidant effect of Rheum ribes extract [1, 4-8]. Some authors reported the antioxidant properties of Rheum ribes extracts [1, 9-11].

As a follow-up to this, we focused on the influence of extraction method on the antioxidative properties of Rheum ribes extracts. as. We used four solvents (methanol, ethanol, acetonitrile and petroleum ether) and four extraction techniques (orbital shaker, ultrasonic stirrer, microwave and Soxhlet extraction) to figure out which method was more efficiently for the antioxidant activity. The antioxidative properties were examined by using spectrophotometric methods, i.e. 2,2-diphenyl-2picryl-hydrazyl free radical scavenging (DPPH) and Ferric Reducing Antioxidant Power (FRAP) assays [9]. In addition, Folin-Ciocalteu modified method was used for determining the total phenolic content [10-12].

\section{Experimental}

The roots of Rheum ribes were purchased from a local market in Urfa, Turkey. Folin-Ciocalteu's reagent, iron (III) chloride hexahydrate, methanol, ethanol, acetonitrile, petroleum ether and sodium carbonate were purchased from Merck (Darmstadt, Germany). 2,2Diphenyl-1-picrylhydrazyl (DPPH), 6-hydroxy-2,5,7,8tetramethylchroman-2-carboxylic acid (Trolox), gallic acid (GA), and 2,4,6-tris(2-pyridyl)-s-triazine (TPTZ) were obtained from Sigma Chemical Co. (Sigma-Aldrich GmbH, Sternheim, Germany). All chemicals and solvents were of analytical grade. Deionized and pure water (Millipore-Q System) was used for the study.

2.1. Preparation of plant extracts. The extraction procedure was as described by Apak et al. [13]. The roots of Rheum ribes materials were dried at the room temperature and chopped into small parts by using a blender. On $2 \mathrm{~g}$ chopped roots were added $25 \mathrm{~mL}$ of extraction solvent (i.e. 50\% methanol, $70 \%$ ethanol, $80 \%$ acetonitrile, and petroleum ether).

The extraction temperature and time were: $60{ }^{\circ} \mathrm{C}$ and $30 \mathrm{~min}$ for ultrasonic extraction [IU]; $25^{\circ} \mathrm{C}$ and $4 \mathrm{~h}$ for Soxhlet extraction [IS]; $40{ }^{\circ} \mathrm{C}$ and $1 \mathrm{~h}$ for microwaves extraction ( $0.25 \mathrm{~g}$ root powder) [IM]; $25^{\circ} \mathrm{C}$ and $2 \mathrm{~h}$ for orbital shaker extraction [IO]. The extracts were filtered using Whatman blue band filter paper and stored at -20 ${ }^{\circ} \mathrm{C}$ until analysis.

\subsection{Total phenolic content}

Total phenolic content of Rheum ribes was determined with Folin-Ciocalteu reagent according a modified method, using GA as a standard phenolic compound [1217]. In brief, $100 \mu \mathrm{L}$ sample were added to $4.0 \mathrm{~mL}$ of distilled water and $100 \mu \mathrm{L}$ Folin-Ciocalteu reagent, and

\footnotetext{
* Corresponding author. E-mail address: dbilgic@marmara.edu.tr (Dilek Bilgic Alkaya)
} 
the mixture was incubated for $5 \mathrm{~min}$ at $30{ }^{\circ} \mathrm{C} .800 \mu \mathrm{L}$ of $6 \% \mathrm{Na}_{2} \mathrm{CO}_{3}$ solution were added and the mixture was incubated in the amber straight sided beaker for $30 \mathrm{~min}$ at $30{ }^{\circ} \mathrm{C}$. The absorbance was measured in $685-760 \mathrm{~nm}$ domain (i.e. $687 \mathrm{~nm}$ for methanol extract, $688 \mathrm{~nm}$ for ethanol extract, $685 \mathrm{~nm}$ acetonitrile extract and $686 \mathrm{~nm}$ fore petroleum ether extract) by using a spectrophotometer (UV 1601, Shimadzu Co., Ltd., Kyoto, Japan) [16].

The results were expressed as gallic acid equivalent equivalents (GAE, mg of GA per $1 \mathrm{~mL}$ sample) $[8,9]$. The calibration equation for GA is $A=0.0019 \mathrm{x}+0.0095$ $\left(R^{2}=0.9996\right)$. Each test was repeated three times.

\subsection{Determination of radical scavenging ability by using DPPH method}

The DPPH radical scavenging assay was applied by Marinova [15] and was later modified by Yilmaz and Seyhan [16] with some minor changes. In brief, $1.5 \mathrm{~mL}$ of the extract were mixed with $1.5 \mathrm{~mL}$ of $0.1 \mathrm{mM} \mathrm{DPPH}$ solution (in methanol). The reaction mixture was incubated at $30{ }^{\circ} \mathrm{C}$ for $30 \mathrm{~min}(200 \mathrm{rpm})$. The absorbance was measured in 515-528 nm domain (i.e. $521 \mathrm{~nm}$ for methanol extract, $515 \mathrm{~nm}$ for ethanol extract, $525 \mathrm{~nm}$ acetonitrile extract, and $528 \mathrm{~nm}$ for petroleum ether extract) by using spectrophotometer. The results were expressed as millimolar of Trolox equivalent antioxidant capacity (TEAC) per $1 \mathrm{~mL}$ sample. The calibration equation for Trolox is $A=-0.0134 \mathrm{x}+0.6375\left(R^{2}=\right.$ $0.9951)$. Each test was repeated three times.

\subsection{Ferric reducing/antioxidant power assay}

We used the method described by Benzie and Strain [17] with some modifications. The working solutions were used on the day of preparation. FRAP reagent: acetate buffer (300 mM, pH 3.6), tripyridyltriazine (TPTZ) (10 $\mathrm{mM}$ in $\mathrm{HCl}, 40 \mathrm{mM})$ and $\mathrm{FeCl}_{3}(20 \mathrm{mM})$. The required sample was added to the FRAP reagent $(1: 30, \mathrm{v}: \mathrm{v})$ and incubated at $37{ }^{\circ} \mathrm{C}$ for $4 \mathrm{~min}$. The absorbance of the reaction mixture was read at $596 \mathrm{~nm}$ for methanol extract, $597 \mathrm{~nm}$ for ethanol extract, $597 \mathrm{~nm}$ acetonitrile extract, and $595 \mathrm{~nm}$ for petroleum ether extract. The antioxidant capacity, based on the ability of the sample to reduce ferric ions, was expressed as millimolar Trolox equivalents per sample by using a calibration curve [14]. The calibration equation for Trolox is $A=0.0011 \mathrm{x}+$ $0.1188\left(R^{2}=0.9893\right)$. Each test was repeated three times.

\section{Results and discussion}

The antioxidant potential of Rheum ribes extracts, obtained by four extraction methods and also in different solvents, was evaluated and the results were compared.

\subsection{Total phenolic content}

The values of total phenolic content for analyzed samples are presented in Fig. 1. The ethanol extract of Rheum ribes showed the highest phenolic concentration, and contrarily the petroleum extract of this plant showed lowest antioxidant activity. As indicated in Fig. 1, the total polyphenols values varied from 0.30 to $1.22 \mathrm{mg}$ $\mathrm{GAE} / \mathrm{mL}$.

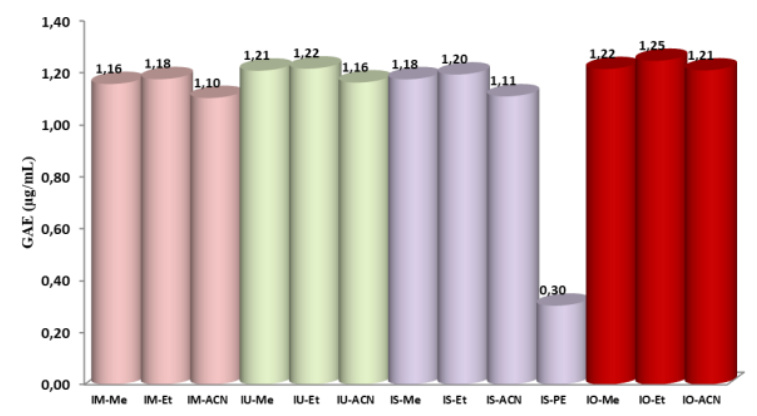

Figure 1. Total phenolic content in the Rheum ribes extracts expressed in terms of GAE.

\subsection{Antioxidant capacity}

The antioxidant capacity of Rheum ribes species were widely studied in vitro by DPPH and FRAP methods. To the best of our knowledge, some authors have been reported that this plant has antioxidant activity and a potential activity to protect the body from some diseases [7, 18-25].

The FRAP values of studied samples are shown in Fig. 2. The best antioxidant capacity was acquired using ethanol. Contrarily, petroleum ether extracts contain considerably smaller concentration of phenols. As indicated in Fig. 2, the FRAP values varied from 8.88 to $62.70 \mathrm{mM}$ Trolox/mL.

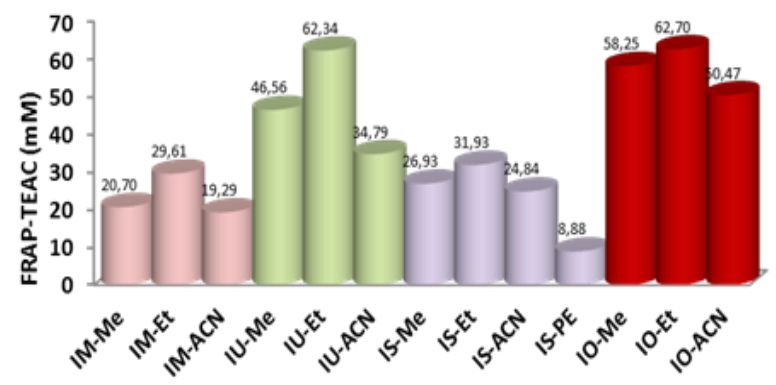

Figure 2. FRAP values for Rheum ribes extracts.

The DPPH values of samples are shown in Fig. 3. The higher value was determined for ethanolic extract. By contrast, the lowest antioxidant capacity was obtained by using petroleum ether as solvent. As indicated in Fig 3, the DPPH values varied from 2.84 to $28.98 \mathrm{mM}$ $\mathrm{TEAC} / \mathrm{mL}$.

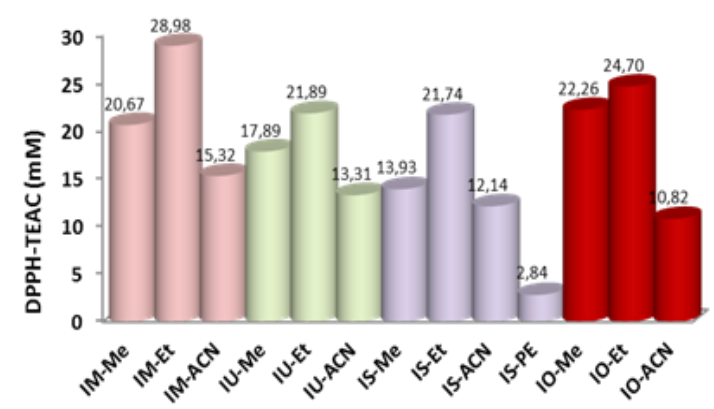

Figure 3. DPPH scavenging activity of investigated Rheum ribes extracts.

\section{Conclusion}

The antioxidant potential of the Rheum ribes extracts was evaluated using different antioxidant tests. According to 
the results, the ethanol extract showed high antioxidant activity. Therefore, this ethanol fraction will have highest amount of antioxidant compounds which are thought to be phenol in nature. In addition, among the four extraction methods were compared, ultrasound and microwave extract techniques showed the best results.

Particularly, the petroleum ether extract was found to be the less active. The polyphenol extracted in the optimum conditions showed high antioxidant activities in vitro. Therefore, polyphenol concentrates with high phenolic contents and powerful antioxidant properties can be obtained from roots of Rheum ribes using the optimized conditions. For the medicinal properties of this plant due to its antioxidant potential further in vivo studies of these species are required.

\section{Conflict of interest}

The authors declare no conflict of interest.

\section{References}

[1]. M. Ozturk, F.A. Ozturk, M.E. Duru, G. Topçu, Antioxidant activity of stem and root extracts of Rhubarb (Rheum ribes): An edible medicinal plant, Food Chemistry 103 (2007) 623-630.

[2]. B.E. Abu-Irmaileh, F.U. Afifi, Herbal medicine in Jordan with special emphasis on commonly used herbs, Journal of Ethnopharmacology 89 (2003) 193-197.

[3]. M. Zahedi, M.R. Hojjati, H. Fathpour, Z. Rabiei, Z. Alibabaei, A. Basim, Effect of Rheum ribes hydroalcoholic extract on memory impairments in rat model of Alzheimer's disease, Iranian Journal of Pharmaceutical Research 14 (2015) 1197-1206

[4]. M. Oktay, A. Yıldırım, V. Bilaloglu, İ. Gülçin, Antioxidant activity of different parts of isgin (Rheum ribes L.), Asian Journal of Chemistry 19 (2007) 3047-3055.

[5]. A.S Łetowska, A.Z Kucharska, A. Biesiada, Antioxidant activity and total phenolic content of Rheum palmatum roots, Kerva polonica 55 (2009) 200-205.

[6]. K.A. Khalida, M.T. Ekhlass, M.R. Saleh, Phenolic profile, antioxidant, and antibacterial effects of ethanol and aqueous extracts of Rheum ribes $\mathrm{L}$. roots, Der Pharmacia Lettre 7 (2015) 26-30.

[7]. A.M. Alaadin, E.H. Al-Khateeb, A.K. Jigar, Antibacterial activity of the Iraq Rheum ribes, Pharmaceutical Biology 45 (2008) 688-690.

[8]. P. Uyar, N. Coruh, M. İscan, Evaluation of in vitro antioxidative, cytotoxic and apoptotic activities of Rheum ribes ethyl acetate extracts, Journal of Plant Sciences 2 (2014) 339-346.

[9]. S.E. Tanrikut, B. Ceken, S. Altas, M. Pirinccioglu, G. Kizil, M. Kizil, DNA cleavage protecting activity and in vitro antioxidant potential of aqueous extract from fresh stems of Rheum ribes, Acta Alimentaria 42 (2013) 461-472.

[10]. I.H. Mohammed, E.S. Kakey, M.M Farimani, In vitro evaluation of antioxidant activates for parts of rhubarb (Rheum ribes) and Syrian mesquite
(Prosopis farcta), International Conference on Pure and Applied Sciences (2019) 14-18.

[11]. S. Keser, F. Keser, M. Karatepe, O. Kaygili, S. Tekin, I. Turkoglu, E. Demir, O. Yilmaz, S. Kirbag and S. Sandal, Bioactive contents In vitro antiradical, antimicrobial and cytotoxic properties of rhubarb (Rheum ribes L.) extracts, Natural Product Research Formerly Natural Product Letters 19 (2018) 1-5.

[12]. A. Karadag, B. Ozcelik, S. Saner, Review of methods to determine antioxidant capacities. Food Analytical Methods 2 (2009) 41-60.

[13]. K. Güçlü, M. Altun, M. Özyürek, S.E. Karademir, R. Apak, Antioxidant capacity of fresh, sun- and sulphited-dried Malatya apricot (Prunus armeniaca) assayed by CUPRAC, ABTS/TEAC and Folin methods, International Journal Food Science Technology 41 (2006) 76-85.

[14]. N.P. Visavadiya, S. Badrish, D. Nirav, Evaluation of antioxidant and antiatherogenic properties of Glycyrrhiza glabra root using in vitro models, International Journal of Food Science Nutrition 60 (2009) 135-49.

[15]. G. Marinova and V. Batchvarov, Evaluation of the methods for determination of the free radical scavenging activity by DPPH, Bulgarian Journal of Agricultural Science 17 (2011) 11-24.

[16]. D.Ç. Y1lmaz and S.A. Seyhan, Antioxidant potential of Cydonia oblonga leaves, Istanbul Journal of Pharmacy 47 (2017) 9-11.

[17]. I.F. Benzie, J.J. Strain, Ferric reducing/antioxidant power assay: direct measure of total antioxidant activity of biological fluids and modified version for simultaneous measurement of total antioxidant power and ascorbic acid concentration, Methods in Enzymology 299 (1999) 15-27.

[18]. K. Slinkard, V.L. Singleton, Total phenol analysis: Automation and comparison with manual methods, American Journal of Enology and Viticulture 28 (1977) 49-55.

[19]. D.J. Huang, B.X. Ou, R.L. Prior, The chemistry behind antioxidant capacity assays, Journal of Agricultural Food Chemistry 53 (2005) 1841- 56.

[20]. G. Zengin, Y.S. Selim Cakmak, G. Ozmen, G.A. Aktum, In vitro antioxidant capacities and fatty acid compositions of three Centaurea species collected from Central Anatolia region of Turkey, Food and Chemical Toxicology 48 (2010) 2638-2641.

[21]. R.L. Prior, X. Wu, K. Schaich, Standardized methods for the determination of antioxidant capacity and phenolics in foods and dietary supplements, Food Chemistry 53 (2005) 42904302.

[22]. C. Sánchez-Morenoa, J.A. Larraurib, F. SauraCalixtoa, Free radical scavenging capacity and inhibition of lipid oxidation of wines, grape juices and related polyphenolic constituents, Food Research International 32 (1999) 407-412.

[23]. C. Chen, W. Hu, R. Zhang, A. Jiang, Y. Zou, Levels of phenolic compounds, antioxidant capacity, and microbial counts of fresh-cut onions after treatment with a combination of nisin and 
citric acid, Horticulture Environmental and Biotechnology 57 (2016) 266-273.

[24]. L. Fu, B.T. Xu, X.R. Xu, R.Y. Gan, Y. Zhang, E.Q. Xia, H.B. Li, Antioxidant capacities and total phenolic contents of 62 fruits, Food Chemistry 129 (2011) 345-350.

[25]. D. Krishnaiah, R. Sarbatly, R.A. Nithyanandam, Review of the antioxidant potential of medicinal plant species, Food and Bioproducts Processing 89 (2011) 217-233.

Received: 06.02.2019

Received in revised form: 22.04.2019

Accepted: 25.04.2019 